\title{
The use of strain threshold in slope stability trigger action response plans
}

\author{
S Coetsee Reutech Mining, South Africa \\ R Armstrong SRK Consulting (South Africa) (Pty) Ltd, South Africa \\ P Terbrugge SRK Consulting (South Africa) (Pty) Ltd, South Africa
}

\begin{abstract}
The measurement of pit slope displacement and the interpretation of subsequent movement and deformation patterns is a well-established industry practice and forms the principal element of a pit slope monitoring program.

The collected displacement data may be interpreted as the total accumulated displacement since the onset of measurement. The average velocity and the velocity delta values (both acceleration and deceleration) can be calculated from the displacement data in order to assist in the identification of slope instability and for the assessment of slope performance.

The strain component of a pit slope, when assessed in the form of the strain criteria for the total or a portion of accumulated displacement, can depict the key stages of instability based on empirical examples from a variety of failure modes and geotechnical settings.

The strain-based approach of assessing slope stability has relied on the traditional strain criteria formula. However, by rearranging the formula to solve the displacement value based on a pre-selected strain percentage and a defined slope height, an indicative displacement value can be applied to proactively evaluate the displacement history of the pit slope. This evaluation can be for a variety of movement and deformation transitions.

It is through this approach that the operation trigger action response plan can be populated to include indicative guidelines for strain threshold alarms utilising displacement measurements as a proxy. The average velocity and velocity delta values can then be determined for hourly or daily limits. This approach allows for a revised strategy for monitoring pit slope performance and instability monitoring and mitigation which incorporates strain.
\end{abstract}

Keywords: strain criteria, slope instability, trigger action response plan, relative range, average velocity, velocity delta

\section{Introduction}

The measurement of pit slope displacement and the interpretation of subsequent movement and deformation patterns is a well-established industry practice and forms the principal element of a pit slope monitoring program.

The collected displacement data may be interpreted as the total accumulated displacement since the onset of measurement. The average velocity and the velocity delta values (both acceleration and deceleration) can be calculated from the displacement data in order to assist in the identification of slope instability and for the assessment of slope performance.

The strain component of a pit slope, when assessed in the form of the strain criteria for the total or a portion of accumulated displacement, can depict the key stages of instability based on empirical examples from a variety of failure modes and geotechnical settings. 
The strain-based approach of assessing slope stability has relied on the traditional strain criteria formula. However, by rearranging the formula to solve the displacement value based on a pre-selected strain percentage and a defined slope height, an indicative displacement value can be applied to proactively evaluate the displacement history of the pit slope. This evaluation can be for a variety of movement and deformation transitions.

It is through this approach that the operation trigger action response plan can be populated to include indicative guidelines for strain threshold alarms utilising displacement measurements as a proxy. The average velocity and velocity delta values can then be determined for hourly or daily limits. This approach allows for a revised strategy for monitoring pit slope performance and instability monitoring and mitigation which incorporates strain.

The term 'strain' describes the ability of a stressed material, in the presence of a stress field, to deform. When a slope is excavated, the rock mass succumbs to the application of stress which is due to the rearrangement of the natural in situ stress field, which in turn, is determined by the slope geometry and slope construction.in situ stress conditions. The steeper the slope, the higher the stress load. As a result of stress redistribution, localised stress concentrations can result in strain in the rock mass which may lead to instability, such as an increase in stress, particularity at the toe of the slope along with stress relaxation in areas where confinement has been lost.

The principal parameters used to measure the strain of a material are known as the strain rate (strain per unit of time), the elasticity (recoverable strain) and the plastic (non-recoverable and accumulative strain) (Pluijm \& Marshak 2004).

For the purpose of clarity, displacement is the measurement of a point on the pit slope which can be either negative (when the distance between the measuring device and pit slope is reduced, suggesting movement towards the measurement device) or positive (when the distance between the measuring device and pit slope is increased, suggesting movement away from the measurement device). In the case of the measurement of a prism, the measurement is true three-dimensional (3D) vector data and in terms of real aperture radar, the data point is measured in 3D space, however, the displacement data collected is resolved in terms increasing or decreasing distance from the sensor.

Movement is described as the act of the pit slope wall physically changing position in terms of displacement and time and may be fitted into a movement class. Deformation is the interpretation of the displacement and thus the calculated strain component of the movement. The characteristics of the movement and deformation can take the form of pre-identified patterns that can be observed on a displacement trend over time.

When stress and strain are put into the context of an open pit environment, it is understood that the rock mass will undergo stress relaxation due to the unloading of the excavated material throughout the life-of-mine. The associated strain rates may fit into pre-defined movement or deformation stages but these stages are dependent on the variety of internal and external factors.

The pit slope monitoring program should record the displacement of the pit slope from as early as possible. By documenting the location, displacement and date at which the displacement was measured, regardless of the technique utilised, the accumulated displacement, average velocity and velocity delta parameters can be calculated for a detailed assessment of the pit slope condition. 


\section{The strain criteria: an overview}

This strain-based approach to assessing pit slope stability utilises the fundamental principles of the strain formula. This paper builds on the method presented by Brox \& Newcomen (2003) with an updated paper further detailing the subject by Newcomen \& Dick (2016). For the purpose of their criteria, they define the strain of a slope as:

$$
\varepsilon=\Delta x / H
$$

where:

$$
\begin{aligned}
& \Delta x=\text { the maximum deformation of the highwall. } \\
& H \quad=\text { the total height of the highwall. } \\
& \varepsilon \quad=\text { the strain and is presented as a percentage value. }
\end{aligned}
$$

It is important to appreciate the history and background of the strain criteria approach, thus the principal outcomes of the Brox \& Newcomen (2003) and Newcomen \& Dick (2016), along with pertinent information from other papers (referenced individually), are discussed.

Displacement rates are used to determine progressive versus regressive movement, however, there is a way of also assessing the strain occurring at the excavation face based on surface measurements. The strain criteria approach is based on the empirical correlation of actual strain values from prism monitoring data and observed slope stability performance. Predicted strain values can then be used to assess the slope stability performance for a proposed mining geometry.

Non-elastic relaxation occurs due to the dilation of discontinuities in the rock mass and this component of strain cannot be recovered. In addition, the use of this method does not reflect the total strain experienced by the excavation, as only the surface measurement of displacement is utilised in the formula.

Instability includes planar $(P)$, wedge $(W)$, step-path, toppling $(T)$, rotational/rock mass $(R)$ and complex $(C)$ failure types. These failure types involve different strain levels which are further described, especially with regards to the mechanism and how the monitoring data can be interpreted.

The highwall strain, rock mass quality (Bienawski $\left.1976\left(\mathrm{RMR}_{76}\right)\right)$ and inferred instability mechanism was utilised in order to compile an empirical highwall stability chart. The paper details specific case studies and recommends that they are referred to as examples in order to verify the conditions experienced at the operation in question with a more similar case study, then using the table and graph directly.

Newcomen \& Dick (2016) refine the strain criteria through an updated database, defining 'strain at failure' based on the failure mechanism as well as making the clear definition of failure as being the "complete collapse of the pit wall". The database was improved by removing the case studies that had not collapsed completely. Case studies from the Whitall et al. (2015) study were included in the database which was separated by the instability types $(P, W, T$ and $R$ ) and graphing them accordingly based on the rock mass quality and the highwall strain measured at the time of collapse. $R$ failure was utilised as a category for failures which were poorly defined in terms of mechanism but still warranted inclusion in the assessment.

Newcomen \& Dick (2016) discuss the link between the lower classes of rock mass quality allowing for higher levels of recorded strain and therefore that the deformability of the rock mass (based on the rock mass rating $\mathrm{RMR}_{76}$ ) was made. The strain in the pit slope was defined as the total movement measured at the surface divided by the height of the slope below the prism. It should be noted that the method is an approximation of strain and does not represent the actual strain at the surface or in the pit wall. The approach can potentially underestimate the actual strain, however, it is simple to calculate and considered accurate enough to approximate the surface strain, as long as the surface slope monitoring system was implemented relatively soon after mining was started.

To further explore the relationship between the $\mathrm{RMR}_{76}$ and strain at collapse, the data was divided into two groups, which for ease of reference are illustrated in Figures 1 and 2. 
The graph in Figure 1 indicates that planar failure generally occurs at the lower strain levels and can occur over a relatively wide range of $\mathrm{RMR}_{76}$. Planar failure collapse strain varied between $0.03 \%$ and $0.06 \%$, with the maximum strain measured for a planar failure being approximately 3\% (Newcomen \& Dick 2016).

The data for the wedge failures indicate a minimum strain of $0.2 \%$ and a maximum strain of $6 \%$. Two observed cases had strains greater than $3 \%$. The range of strain for a given $\mathrm{RMR}_{76}$ is smaller for wedge failures than for planar failures (Newcomen \& Dick 2016).

The results for both the planar and wedge category suggest that $3 \%$ may be a reasonable maximum threshold to use for prediction especially in the poor to fair rock mass classes.

Figure 2 illustrates that for toppling and rock mass failure, there is a greater spread of strain for the rock mass class. For rock mass failure, a strain rate of less than $0.1 \%$ was recorded with an upper bound value of $3 \%$. It is suggested that $4 \%$ may be a reasonable maximum strain threshold for non-kinematic failure in the poor to fair rock mass quality classes. (Newcomen \& Dick 2016).

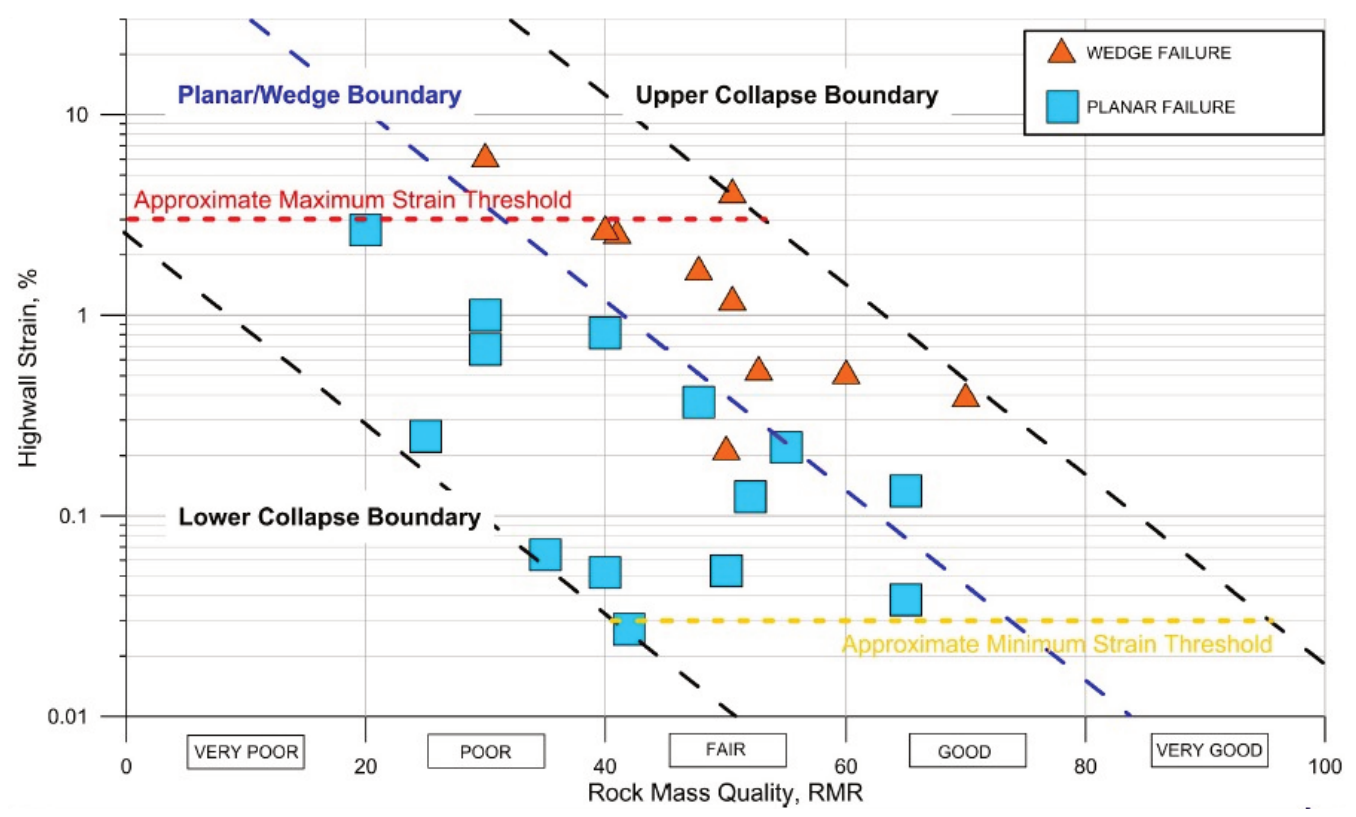

Figure $1 \quad \mathrm{RMR}_{76}$ versus pit wall strain at collapse for planar and wedge failure (Newcomen \& Dick 2016)

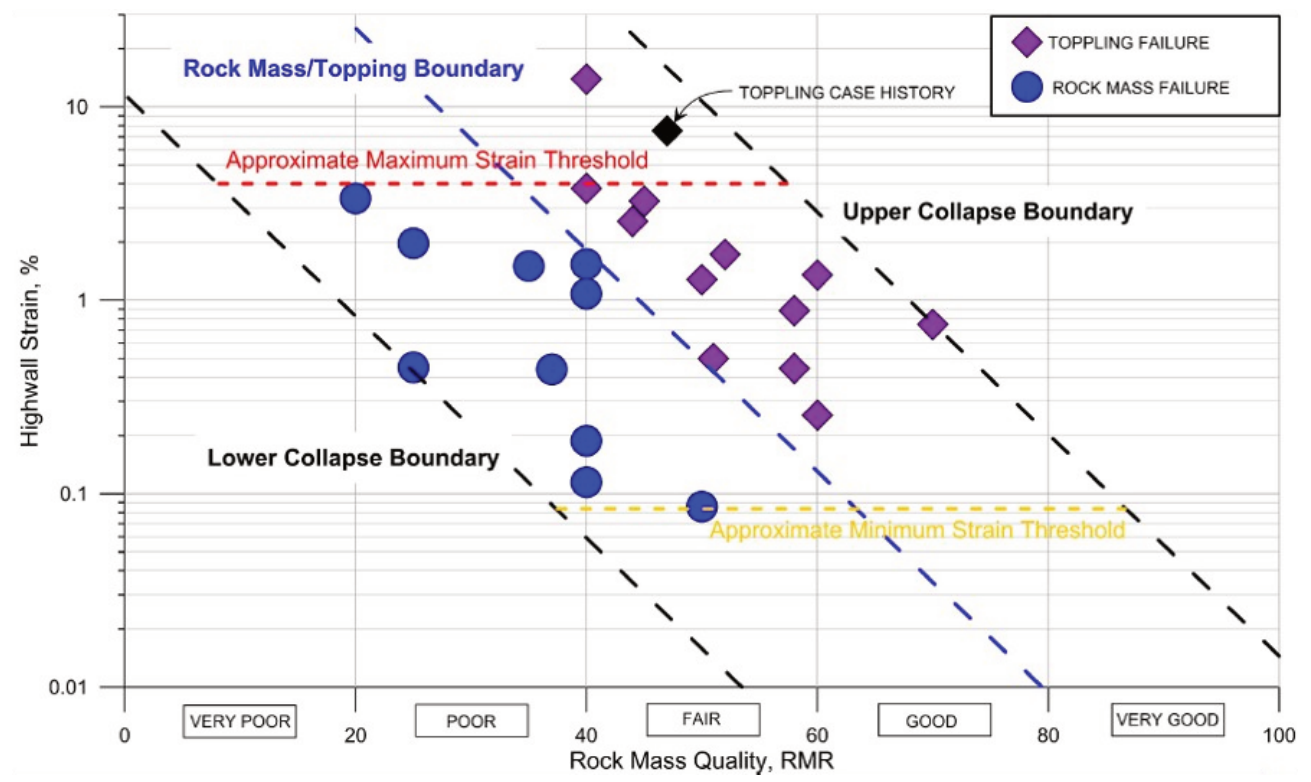

Figure $2 \mathrm{RMR}_{76}$ versus pit wall strain at collapse for toppling and rock mass failure (Newcomen \& Dick 2016) 
With regards to the toppling failure, the highest strain rate recorded was almost $15 \%$, with an average of approximately $4 \%$ measured for most failures. The minimum strain for the toppling failures was between 0.2 and $0.3 \%$. The range of $\mathrm{RMR}_{76}$ is somewhat smaller for the toppling versus the rock mass failure (Newcomen \& Dick 2016).

Rock mass failure is expected to occur in weaker and lower quality rock masses which should therefore exhibit higher levels of strain, however, this may be internalised and not necessarily exhibited on the surface. The constraints of the case studied utilised for this category are taken into consideration.

Zavodni in Hustrulid et al. (2001) suggested 1\%, with Brox \& Newcomen (2003) suggesting 2\%. It is apparent that with more case studies, the maximum strain rate for all failure types collectively, as well as specific failure modes, has been refined further. A starting point of $4 \%$ can be used as a maximum strain point for which a pit slope failure could occur and this is regardless of the mode of failure (Newcomen \& Dick 2016).

When comparing the failure modes, the lowest level of strain at collapse are planar in nature with the highest strain being the toppling failures.

Two points that require further thought for application of this criteria include the fact that the strain at depth or along the failure plane is not captured, and that the degradation of the rock mass over time is not applied as part of a mining rock mass rating.

Zavodni in Hustrulid et al. (2001), Brox \& Newcomen (2003) and Newcomen \& Dick (2016) have given empirical examples of strain percentages for case studies for the principal failure modes in various rock mass classes. Table 1 summarises the range of strain percentages for the failure mode and the rock mass class.

Table 1 Suggested threshold strain levels for key stages of highwall instability (Newcomen \& Dick 2016)

\begin{tabular}{llllll}
\hline $\begin{array}{l}\text { Failure } \\
\text { type }\end{array}$ & $\begin{array}{l}\text { Strain at } \\
\text { collapse (lower } \\
\text { bound) \% }\end{array}$ & $\begin{array}{l}\text { Strain at collapse } \\
\text { (approximate } \\
\text { average) \% }\end{array}$ & $\begin{array}{l}\text { Strain at } \\
\text { collapse (upper } \\
\text { bound) \% }\end{array}$ & $\begin{array}{l}\text { Suggested } \\
\text { maximum } \\
\text { threshold \% }\end{array}$ & $\begin{array}{l}\text { Rock mass } \\
\text { class }\end{array}$ \\
\hline Planar & $0.03-0.06$ & - & 3 & 3 & Poor to fair \\
Wedge & 0.2 & - & 6 & 4 & \\
Toppling & $0.2-0.3$ & 4 & 15 & 4 & \\
Rock mass & 0.1 & - & 3 & & \\
\hline
\end{tabular}

\section{Pit slope movement and deformation}

The rate and scale of movement in the form of velocity or what can also be termed as average velocity is another key parameter for the identification of pit slope instability. The average velocity is a derivative of the accumulated displacement based on a reference time and an assigned time window.

Work conducted by Sullivan (2007) summarises the development of pit slope movement phases and provides a holistic view of the possible stages of pit slope movement from the perspective of velocity. It is paramount to understand the principals of both pit slope movement phases as well as the movement patterns in order to define alarm settings that provide data that is representative of the movement stage for which the pit slope is in.

According to Sullivan (2007), the pit slope movement phases may be defined as elastic, creep, cracking and dislocation, collapse (failure) and post-failure deformation.

These stages are illustrated in Figure 3 for a typical failure as a plot of the velocity versus the time for the slope movement stages with the trigger action response plan (TARP) limits overlaid (refer to Section 5 and Table 4). 
Important features to consider from Figure 3 include:

- The velocity is highly variable with the example of $0.1 \mathrm{~m} /$ day to $10 \mathrm{~m} / \mathrm{sec}$ used by Sullivan (2007), noting that the very high post-failure velocities are indicative of debris flow conditions.

- In order to track the key movement stages of an instability in the form of a TARP, different velocity alarm thresholds can be applied per movement stage, warranted there is enough time which is dependent on the rock mass and failure mode.

- It is important to note that with the application of prism or real aperture radar monitoring that it becomes difficult to measure high velocities due to inherent system constraints. These applications provide a method to track the displacement and subsequent velocity at which the pit slope is moving, but tracking an instability through active failure is dependent on a high level of repeatability of the measurements throughout the failure process. Thus, it is recommended that based on the system constraints, the highest velocity measurable by the sensor is applied as part of the alarm criteria for the pre-collapse stage of the key slope movement stages.

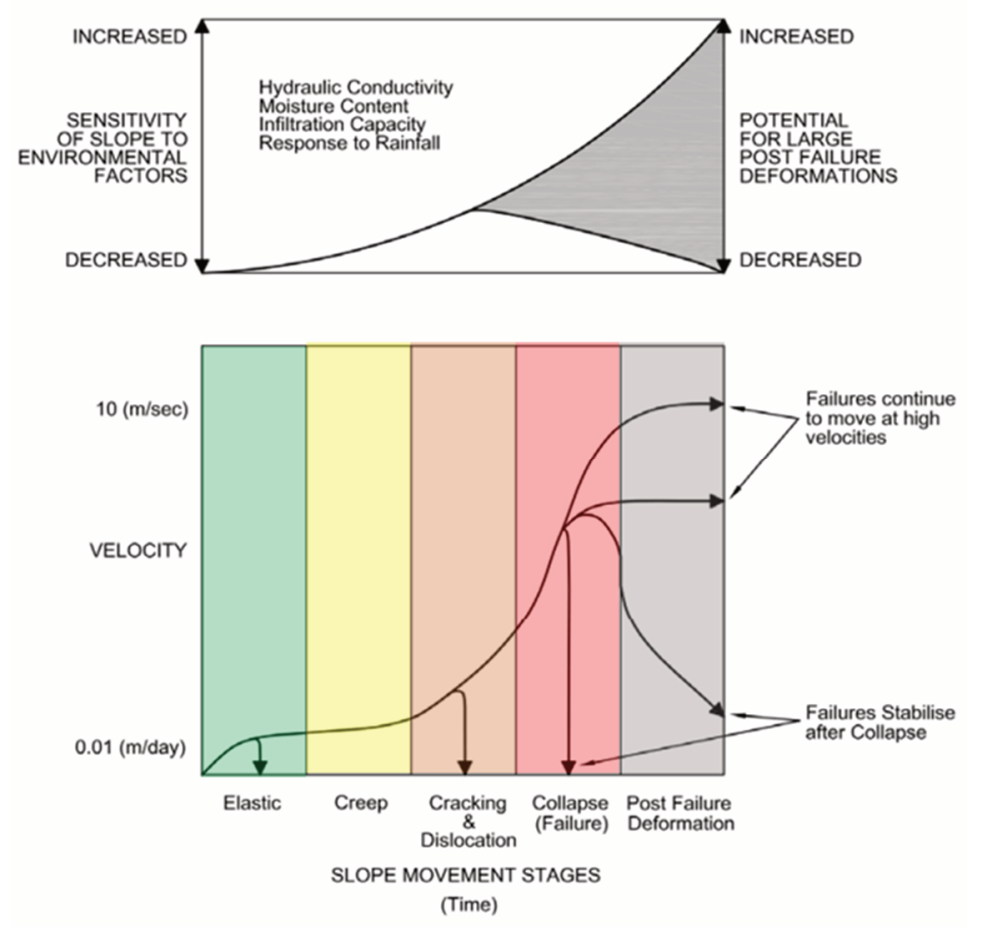

Figure 3 Schematic illustration of the key slope movement stages and change in the hydraulic properties over time (Sullivan 2007) with the trigger action response plan limits overlaid (refer to Table 4)

Having defined the key slope movement stages, it is paramount to understand the behaviour of pit slope movement which is based on the ability of the rock mass in the slope to withstand strain (both internally and on discontinuities). Sullivan (2007) proposed a new pit slope movement classification system which describes the pre-failure, failure and post-failure behaviour for movement patterns. The movement patterns include linear, bi-linear, stick-slip, regressive, transitional, slow accelerating, linear accelerating and accelerating (progressive).

Figure 4 details the movement patterns for pre-failure, failure and post-failure movement with the TARP plan limits overlaid (refer to Section 5 and Table 4). The observations from Sullivan (2007) are described directly:

- In the period leading up to and immediately prior to failure, three types of general behaviour have been observed:

- A long period of continuous acceleration with movements best described by a Power Law. This period is usually measured in weeks to years. 
- A shorter period of acceleration with a lower total displacement prior to collapse and usually measured in days to weeks.

- Failures that occur over very short periods and usually with minimal acceleration observed prior to collapse with displacement measured in minutes to days.

- The post-failure period is illustrated with three examples:

- High velocity failures of the order of $10 \mathrm{~m}$ per second.

- Failures that show moderate and cyclic velocities post-failure.

- Failures that stop after collapse with minimal further movement.
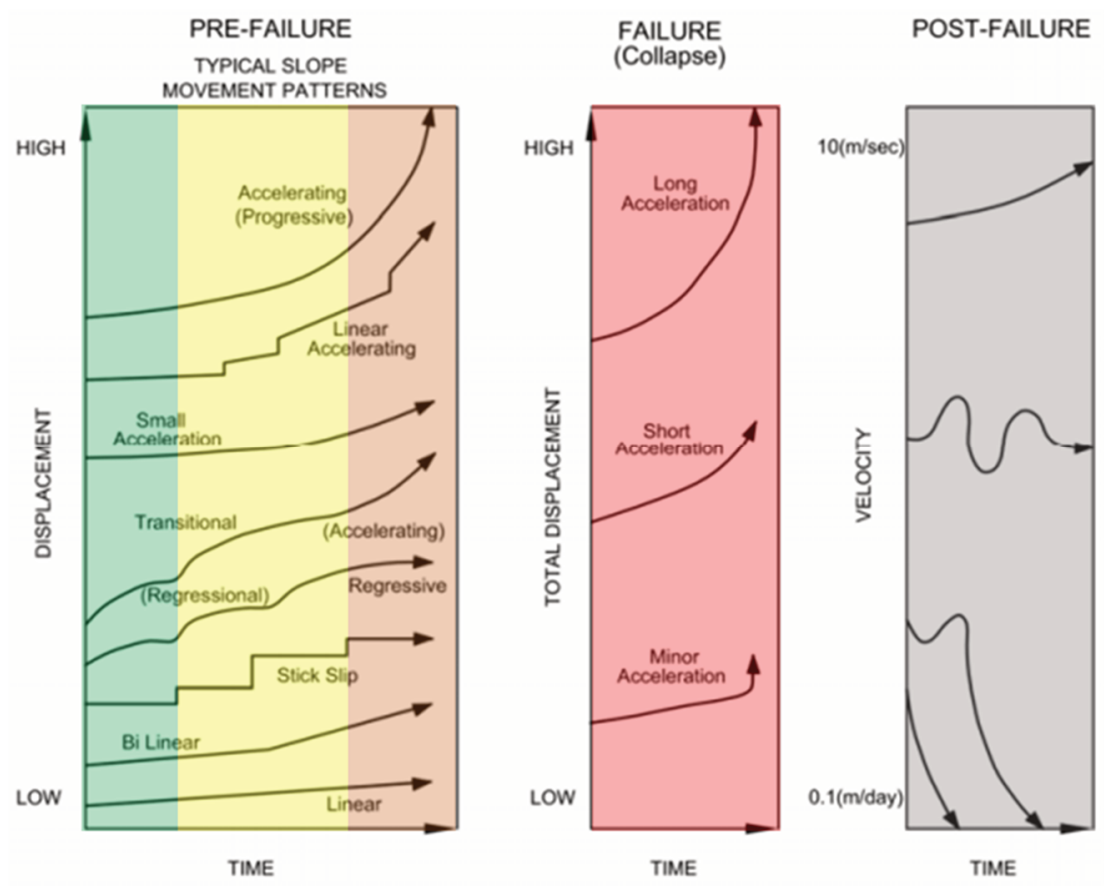

Figure 4 Pre-failure, failure and post-failure movement patterns (Sullivan 2007) with the trigger action response plan limits overlaid (refer to Table 4)

Sullivan (2007) also proposed the classification of pit slope velocities for planning as well as for the determination of critical velocities when imminent failure is expected. The classification data is presented in Tables 2 and 3, respectively. Both tables have been updated to include $\mathrm{mm} / \mathrm{hr}$. For Table 3, the total strain for the recommended period was calculated as total displacement to be measured by means of example, for comparison of derived displacement values for alarm application. 
Table 2 Classification of pit slope velocities for planning (Sullivan 2007)

\begin{tabular}{|c|c|c|c|c|c|}
\hline \multirow[t]{2}{*}{ Movement class } & \multicolumn{3}{|c|}{ Parameter } & \multirow[t]{2}{*}{ Comment } & \multirow{2}{*}{$\begin{array}{l}\text { Sensitivity to } \\
\text { environmental } \\
\text { factors, e.g. } \\
\text { blasting, rainfall, } \\
\text { runoff, etc. }\end{array}$} \\
\hline & $\begin{array}{l}\text { Average } \\
\text { velocity } \\
(\mathrm{mm} / \mathrm{hr})\end{array}$ & $\begin{array}{l}\text { Average } \\
\text { velocity } \\
\text { (mm/day) }\end{array}$ & $\begin{array}{l}\text { Displacement } \\
\text { (mm/month) }\end{array}$ & & \\
\hline Low creep & 0.002 & $<0.05$ & $<1.5$ & $\begin{array}{l}\text { Also possibly Stage } 1 \\
\text { movements }\end{array}$ & Very low \\
\hline Significant creep & $0.002-0.004$ & $0.05-0.1$ & $1.5-3$ & $\begin{array}{l}\text { Also possibly Stage } 1 \\
\text { movements }\end{array}$ & Low \\
\hline $\begin{array}{l}\text { Definite movement } \\
\text { of slope related to } \\
\text { shear or } \\
\text { displacement on } \\
\text { structures }\end{array}$ & $0.004-0.01$ & $0.1-0.25$ & $3-7.5$ & $\begin{array}{l}\text { Could stabilise if } \\
\text { strain hardening }\end{array}$ & Medium \\
\hline $\begin{array}{l}\text { Likely to fail } \\
\text { sometime in the } \\
\text { future }\end{array}$ & $0.01-0.02$ & $0.25-0.5$ & $7.5-15$ & - & Medium to high \\
\hline $\begin{array}{l}\text { High chance of } \\
\text { failure }\end{array}$ & 0.041 & 1 & 30 & - & Medium to high \\
\hline $\begin{array}{l}\text { Pre-failure collapse } \\
\text { movements }\end{array}$ & $<0.041$ & $>1.0$ & $>30$ & - & High \\
\hline
\end{tabular}

Table 3 Classification of pit slope velocities for the detection of critical velocities (Sullivan 2007)

\begin{tabular}{|c|c|c|c|c|c|}
\hline Author & $\begin{array}{l}\text { Average } \\
\text { velocity } \\
\text { (mm/day) }\end{array}$ & $\begin{array}{l}\text { Average } \\
\text { velocity } \\
(\mathrm{mm} / \mathrm{hr})\end{array}$ & $\begin{array}{l}\text { Period over } \\
\text { which velocity } \\
\text { applies (days) }\end{array}$ & $\begin{array}{l}\text { Period over which } \\
\text { velocity applies } \\
\text { (hours) }\end{array}$ & $\begin{array}{l}\text { Total displacement } \\
\text { for the } \\
\text { recommended } \\
\text { period (mm/day) }\end{array}$ \\
\hline \multirow[t]{2}{*}{ Ryan \& Call (1992) } & 12 & 0.50 & 2 & 48 & 24.00 \\
\hline & 50 & 2.08 & 2 & 48 & 100.00 \\
\hline Zavodni (2001) & 17 & 0.71 & 2 & 48 & 34.00 \\
\hline Zavodni (2001) & 15 & 0.63 & - & - & - \\
\hline Martin (1993) & $10-100$ & $0.41-4.16$ & - & - & - \\
\hline $\begin{array}{l}\text { Broadbent \& Zavodni } \\
\text { (1982) }\end{array}$ & 50 & 2.08 & 2 & 48 & 100.00 \\
\hline $\begin{array}{l}\text { Zavodni (2001) Borax } \\
\text { Mine }\end{array}$ & 150 & 6.25 & - & - & - \\
\hline $\begin{array}{l}\text { Call \& Nicholas (from } \\
\text { Zavodni 2001) }\end{array}$ & 300 & 12.50 & - & - & - \\
\hline Savely (1993) & $30-1,000$ & $1.25-41.67$ & - & - & - \\
\hline Sullivan (1993) & $1,000^{*}$ & 41.67 & $<$ hours & $<$ hours & - \\
\hline
\end{tabular}

*Minimum instantaneous velocity immediately prior to collapse 


\section{$4 \quad$ The strain criteria: solving for the displacement value}

By utilising the pre-identified strain percentages and the height of the slope, the derivation of indicative strain displacement thresholds for slope performance and instability monitoring can be calculated. With this approach, the displacement may be defined as:

$$
\Delta x=\varepsilon H
$$

where:

$\Delta x=$ the deformation or displacement value calculated for the slope.

$H \quad=$ can be the total height of the slope, the height above the measurement point or the height of the identified instability (this is based on the assessment of the area of interest).

Strain $(\varepsilon)$ is presented as a percentage value. The deformation value can be utilised as an indicator of the displacement value that an instability will transition through during the key stages of movement. This is a proxy-based relationship which utilised the displacement values measured, utilising either a prism or a radar-based monitoring system.

By separating the strain levels for the particular failure mode and therefore the indicative displacement value into time-dependent displacement behaviour, a TARP can be developed. The alarm criteria can be based on values calculated for the distinct phases of time-dependent deformation and movement experienced pre-failure, failure and post-failure pit slope behaviour.

\section{The trigger action response plan}

In order to compile TARP, a summary of the findings from preceding sections are required in order to include the empirical examples as well as the calculated alarm threshold values. The points to take into consideration when assigning derived indicative strain displacement thresholds for slope performance and instability monitoring include:

- The strain criteria has been developed to include empirical examples with more definitive strain data per failure mode. Section 2 discusses the development of the strain criteria theory and Table 1 details the suggested strain thresholds for the failure types for the poor to fair rock mass class. The case studies presented in the Brox \& Newcomen (2003) paper are useful for comparing site-specific conditions and the strain rate and different parts of the movement stages. Figures 1 and 2 provide the $\mathrm{RMR}_{76}$ versus pit wall strain for the failure types which allows for a more comprehensive assessment of the strain rate per rock mass class.

- Whilst Table 1 and Figures 1 and 2 provide the slope strain at collapse for the failure mode for the rock mass class, the strain rates for key movement stages are not defined.

- Section 3 discusses pit slope movement and deformation in terms of slope movement stages which illustrates that in order to track key movement stages of instability, different average velocity (and therefore displacement and velocity delta) alarm thresholds are required to identify movement classes. Identifying movement classes allows for an appreciation of the slope behaviour through the instability tracking process.

- Overprinted on top of the key movement stages is the pattern of the movement as defined by the ability of the pit slope to withstand strain (both internally and on discontinuities). The classification data presented in Tables 2 and 3 have been updated to include $\mathrm{mm} / \mathrm{hr}$ and the total strain for the recommended period was calculated as total displacement to be measured for ease of reference. The values supplied are useful and a basis for comparison when setting up or refining a TARP.

- Section 4 explains the formula for utilising a pre-selected strain percentage for the specific mode of failure and converting this to a displacement value which can, in turn, be utilised as an alarm setting. 
All of the examples presented so far are empirical. However, there are other ways to delineate alarm thresholds for the TARP. These include:

- The assessment of case studies at nearby operations in a similar geotechnical environment.

- The back-analysis of collapsed instabilities experienced onsite. These case studies will allow for a comprehensive assessment of the displacement, average velocity and velocity delta data in collaboration with a geotechnical model and an understanding of the mode of failure and respective failure parameters.

- The assessment of ongoing current database trends in collaboration with the methods described in Sections 2, 3 and 4 .

The identification of potential trigger mechanisms is also vital when assigning alarm thresholds, as each trigger warrants a specific response and will induce different movement and pattern behaviour should an instability become active. Trigger events include, but are not limited to, adverse weather such as high rain or snowfall, melt, freeze and thaw, contraction and dilation, blasting, excavation of the toe, loading of a particular portion of the slope, machinery vibration and seismic events.

With regards to blasting, the damage can extend behind the slope face and can influence the stability of the geological structures in that volume of rock mass. Blast-related damage includes extension of existing fractures, creation of additional fractures (by opening closed geological features or the creation of new blast fractures), displacement of structural surfaces resulting in a loss of cohesion and friction and the creation of instantaneous excess porewater pressure (Coetsee 2014). The rock mass quality rating needs to be adjusted to take the effects of mining and longer-term weathering and deterioration into account.

The TARP presented in Table 4 includes:

- A TARP template that allows for the tracking of pit slope movement stages or an active instability according to the movement stage, pit slope and movement pattern operations as well as relative range, average velocity and velocity delta data.

- The TARP should include the response component per alert level specific to the standard operating procedures at the operation which include dispatch, geotechnical input, pit supervisors and management.

- An alert level which is separated into green, yellow, orange, red and grey. These levels of alert level can be adjusted by the operation as required per movement type.

- The movement class types are segregated and described in terms of the pit slope and movement pattern observation. Once again, these descriptions can be further refined by geotechnical domain or instability that is being back analyses or being currently assessed.

- The +/- alarm threshold level indicates the movement type from the sensor, negative being towards the sensor and positive being away from the sensor (this may depend on the sensor being utilised and needs to be checked and communicated).

- Strain (\%) values selected based on empirical, back-analysis or database trends.

- An indicative strain value may be selected and applied per alert and therefore the movement class type as a percentage and then calculated into millimetres with the recommended displacement threshold for that alert level being set.

- The time window should be separated into longer durations for the earlier stages of movement, to shorter durations leading up to collapse. Longer time windows allow for smoother data trends and therefore less sensitive alarming thresholds, whereas shorter duration time windows are more sensitive to discrete displacement trends. 
- The average velocity, much like the displacement value, can be derived from empirical, back-analysis or the assessment of current database trends. The total strain value can also be divided by the anticipated stand-up time of the pit slope, and segregated into an average velocity allocated per day or per hour. This in turn can be compared with empirically or derived values.

- The velocity delta alarm thresholds should be applied in order to define acceleration or deceleration between average velocity movement classes.

When utilising the TARP presented in Table 4, the following points are pertinent:

- It is recommended that a TARP is set up per geotechnical domain based on the outcome of the kinematic and subsequent geotechnical design outcomes. These geotechnical domains should typically encompass a specific potential instability portfolio for which the alarm thresholds may be set, starting off with the anticipated strain component.

- Most monitoring systems require an area threshold (or similar terminology) to be applied in order for the mean displacement of an area (defined per threshold size) to exceed the alarm criteria applied. That is, all point data collected in that area threshold must as an average exceed the alarm criteria applied in order for an alarm to be generated. The area threshold should be appointed based on the minimum instability size (typically the height of one bench, width to be determined) in order to detect smaller-scale instabilities.

- When using displacement values from a prism or radar-based monitoring system, it is imperative to recognise the limitations of these systems with regards to the accurate measurement of displacement and the 3D movement component. Radar data has been well utilised as a proxy and is therefore an indicative approach for displacement measurement and strain calculation per movement class. It is recommended that prism and radar data be compared and correlated in order to apply any derived alarm settings to a radar-based system.

- The assignment of alarm threshold criteria for various alarm parameters is a dynamic and not a static 'art' that requires experience in interpreting the local conditions. An approach that consists of continuous, reviewed and implemented improvement should be applied to the TARP per domain as more data and information is collected.

- The most pertinent question that requires further work is that whilst the strain or displacement values are known at complete collapse empirically, what alarm thresholds utilising the strain criteria methodology may be applied in order to provide adequate time for warning of impending complete collapse prior to the event. This is the transition zone between the cracking and dislocation movement stage and that of complete collapse.

- While absolute displacement values are required to set alarm levels in modern monitoring systems, the existence of alarms or alarm levels do not exempt the geotechnical practitioner from regularly assessing and analysing the monitoring data. The synthetic data display maps and trends should be examined for discrete trends that may not have met the alarm threshold criteria in order to trigger an alarm. Similarly, when an alarm has been triggered, the alarm may not represent the maximum amount of the displacement from the perspective of a single selected point. Therefore, the trend plot and scale on the synthetic data map need to be assessed to appreciate the full measure of movement.

- Any sudden changes in or trend data should be investigated, even if they are below the set alarm levels. These changes may represent movement patterns that precede instability. The majority of unanticipated instabilities occur when the rock mass behaves in an unexpected manner, the discrete movement patterns have not been recognised, and the alarm criteria have not been adapted accordingly. Apply user-selected areas and point data to assess the data in more detail. If required, create a specified user region that allows for a separate much more sensitive TARP to apply to an emergent instability whereby the rest of the slope may be 'stable'. 
- Should there be a situation whereby sound engineering observation and interpretation denotes a change to the TARP, a geotechnical review panel is required to adapt the TARP. TARPs are compiled based on the 'known' understanding of the geotechnical conditions, and as such, 'unknown' conditions require revised alarm criteria, response planning and mitigation procedures.

- Do not be 'blindsided' by tracking larger scale instability events and overlooking smaller scale instabilities which may rapidly propagate from bench to inter-ramp scale. Ensure that the hazard plan is updated with an identification reference and that the instability in tracked as part of day-to-day operations.

- A reference time may be set to denote the displacement data from the onset of an instability and records the total accumulated displacement in $\mathrm{mm}$ for the instability event.

- In order to compare time window data, compile a table that separates domain, area and point data. Apply different time windows to this data and record the minimum and maximum displacement, average velocity and velocity delta measurements. This table can then provide a guideline on the time window and alarm thresholds per time window that can be applied.

- The strain at collapse refers specifically to the fact that the pit slope has failed. When utilising the strain criteria and having derived a displacement value, it is imperative to apply a revised value to pre-empt and therefore provide adequate warning for the complete collapse of the pit slope. Thus, the point at which the cracking and dislocation movement stage transgresses into the collapse stage should be the time at which complete evacuation of the affected area takes places.

- Note that once an instability has occurred, the displacement value will not destabilise at $0 \mathrm{~mm}$ as does the average velocity or velocity delta measurements. The displacement has occurred and therefore all alarm settings applied after this period for displacement (and the derived strain percentage) will need to take the full accumulated displacement into consideration.

- The displacement data can be categorised into movement stages, thus allowing for the calculation of strain for the different movement classes. The displacement data per movement class can then be divided (by days then hours) and time windowed to attain the recommended average velocity alarm settings. This is an empirical approach, however, by recording the displacement and average velocity values and calculating the strain in a TARP for previous instabilities, this process and the alarm parameters can be refined. 


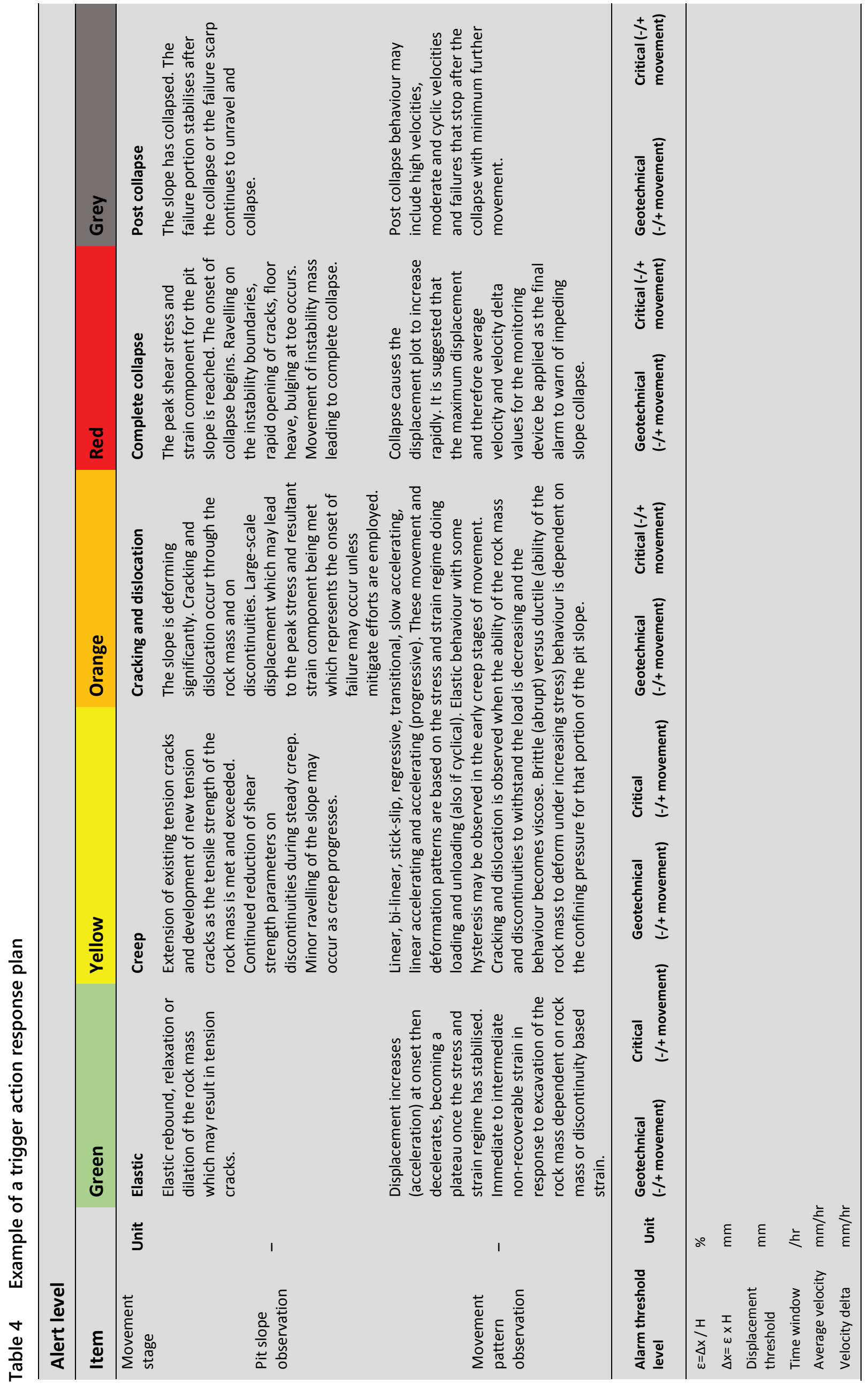




\section{Conclusion}

An overview of the strain criteria and the identification of key movement phases of slope instability and slope deformation patterns was provided. Using this information, in collaboration with the rearrangement of the strain criteria formula to solve for the deformation, or what can be translated as displacement, this allows for the use of these calculated values to be applied in TARPs. Displacement data collected from prism and radar application can be utilised as a proxy to measure displacement for which strain values may be derived to appreciate the strain being accumulated on the surface of a pit slope, which in turn allows for the assessment of slope performance and instability monitoring.

\section{References}

Bieniawski, Z 1976, 'Rock mass classification in rock engineering', in ZT Bieniawski (ed.), Symposium Proceedings of Exploration for Rock Engineering, vol. 1, pp. 97-106.

Broadbent, CD \& Zavodni, ZM 1982, 'Influence of Rock Structure on Stability', Stability in Surface Mining, Society of Mining Engineers. Brox, D \& Newcomen, W 2003, Utilizing strain criteria to predict highwall stability performance', Proceedings of the International Society for Rock Mechanics, The Southern African Institute of Mining and Metallurgy, Johannebsurg, pp. 157-161.

Coetsee, S 2014, 'An overview of bench design for cut slopes', Proceedings of the 8th South African Young Geotechnical Engineers Conference, The South African Institution of Civil Engineers, Stellenboch, pp. 561-571.

Hustrulid, WA, McCarter, MK \& Van Zyl, DJA 2001, Slope Stability in Surface Mining, Society for Mining, Metallurgy \& Expoloration, Littleton, pp. 81-87.

Martin, DC 1993, Time dependent deformation of rock slopes, PhD Thesis, University of London, London.

Newcomen, W \& Dick, G 2016, 'An update to the strain-based approach', Journal of the Southern African Institute of Mining and Metallurgy, vol. 116, no. 5, pp. 379-385.

Pluijm, BA \& Marshak, S 2004, Earth Structure, Norton \& Company Ltd, London.

Read, J \& Stacey, P 2009, Guidelines for Open Pit Slope Design, CSIRO Publishing, Collingwood.

Ryan, TM \& Call, RD 1992, 'Application of rock mass monitoring for stability assessment of pit slope failure', Proceedings of the 33rd U.S. Rock Mechanics Symposium, AA Balkema, Rotterdam, pp. 221-229.

Savely, JP 1993, 'Slope management strategies for successful mining', Innovative Mine Design for the 21st Century, pp. 25-34.

Sullivan, T 1993, 'Understanding pit slope movements', in T Szwedzicki (ed.), Proceedings of the Geotechnical Instrumentation and Monitoring in Open Pit and Underground Mining, Balkema, Rotterdam.

Sullivan, T 2007, 'Hydromechanical coupling and pit slope movements', in Y Potvin (ed.), Proceedings of the 2007 Inyternational Symposium on Rock Slope Stability in Open Pit Mining and Civil Engineering, Australian Centre for Geomechanics, Perth, pp. 3-43.

Whittal, J, Eberhardt, E, Hungr, O \& Stead, D 2015, 'Runout of open pit slope failures using and abusing the Fahrböschung angle', Proceedings of the 2015 International Symposium on Slope Stability in Open Pit Mining and Civil Engineering, The Southern African Institute of Mining and Metallurgy, Johannesburg.

Zavodni, ZM 2001, 'Time-dependent movements of open pit slopes', in WM Hustrulid (ed.), Proceedings of Slope Stability in Surface Mining, Society for Mining, Metallurgy \& Expoloration, Littleton, pp. 81-87. 